\title{
How Do Astronaut Candidate Profiles Differ From Airline Pilot Profiles?
}

\section{Results From the 2008/2009 ESA Astronaut Selection}

\author{
Peter Maschke, Viktor Oubaid, and Yvonne Pecena \\ German Aerospace Center DLR, Hamburg, Germany
}

\begin{abstract}
Sixteen years after the second Europe-wide astronaut selection campaign, the European Space Agency started the third campaign by putting out a call for new astronauts in 2008. Due to extreme environmental conditions, expensive scientific experiments, and high public interest, not only are the psychological requirements on a high level, but they are also wide in variety: Besides cognitive and psychomotor requirements, greater importance than in comparable campaigns was put on personality and behavioral aspects, especially regarding interpersonal aspects. The psychological selection was conducted in two steps: Phase 1 concentrated mainly on performance tests and Phase 2 focused on personality and interpersonal behavior. Out of the 902 tested candidates, 46 fulfilled the psychological requirements. Significant differences were found between the astronaut candidates and the general population as well as airline pilot candidates.
\end{abstract}

Keywords: aviation, space, requirements, pilot selection, astronaut selection

After different national astronaut selection campaigns in Europe, the European Space Agency (ESA) sent out invitations to the first astronaut selection in 1978, for the first Spacelab mission on the US Space Shuttle in 1983. In 1992, the second ESA selection campaign took place (see Fassbender \& Goeters, 1992, 1994; Goeters \& Fassbender, 1992), already planned for preparing ESA's Columbus project (and also for the Hermes project, which was canceled later). In 2008, after 16 years, on the occasion of the launch of the Columbus laboratory, ESA announced the third astronaut selection, to be performed in 2008 and 2009. With a projected 10 years in orbit, Columbus created a need for new astronauts to perform long-term experiments in weightless conditions.

Being a mission specialist in space is an outstanding job position: On long-duration flights (within the next few years aboard the International Space Station [ISS], and later possibly on missions to the Moon and Mars) he/she has to carry out experiments and operate the different systems, to undertake scientific research and serve as a test subject in scientific experiments. All this has to be done subjected to broad public interest and in a hostile environment. Working in space is extreme not only due to the physiological conditions, but also due to psychological requirements: Complex experiments have to be executed, which need a high level of perceptual, cognitive, and psychomotor aptitudes. Errors can have serious consequences - extremely expensive or even life threatening. Specific stress can arise from the long-duration confinement (several months) with no chance to leave the situation.

A satisfactory level of aptitudes is a necessary precondition to meet these different demands, but not a guarantee for high performance at work. Moreover, a high level of general and professional motivation and cooperation is essential. A specific aspect of interpersonal behavior is the necessary ability to communicate within a multicultural team. This is not only a question of language level but also a problem of adaptability and tolerance toward different cultures. So, besides the high level of psychological requirements, their large variety is a specific challenge.

The purpose of this report is to give information about the selection process for the most recent European astronaut recruitment campaign and to present comparisons of the astronaut candidates and appropriate populations.

\section{General Issues in Selecting People to Become Astronauts}

Two different aspects of the selection of astronauts can be distinguished, apart from pure medical selection: Psychiatric selection focuses on selecting out individuals who possess qualities that indicate an increased risk for developing mental or behavioral illness. Psychological selection focuses 
on selecting in individuals who, with respect to their capabilities and personality, seem to be best suited for becoming astronauts and working together in space.

Select-in approaches aim at identifying individuals who, concerning their basic capabilities, personality characteristics, and interpersonal skills, can be expected to meet the specific operational and psychosocial demands of (longduration) space missions. Traditional assessment tools used for this purpose can include performance tests, personality questionnaires, analysis of biographical data, behavioral observations during group exercises, and interviews. In addition, analyses of psychophysiological reactions and individual stress resistance assessed by reactions to specific stressors (e.g., parachute jumping and isolation chamber tests) can be used.

Comparing the different select-in approaches applied in Russia, Canada, Europe, and the United States, there seems to be overall agreement that at least the following aspects need to be considered in evaluating psychological fitness for space flights:

- motivation;

- relevant biographical experiences;

- cognitive and psychomotor capabilities;

- personality traits related to stress coping;

- personality traits related to interpersonal behavior;

- interpersonal and team work skills (e.g., good decision making within the team);

- particularly with regard to ISS missions, cross-cultural competence (see, for more details, Kanes \& Manzey, 2008).

The great importance of "nonoperational aptitudes" also reflects prior research indicating the great importance of attitude and personality for a successful career as an astronaut (see, e.g., Chidester, Helmreich, Gregorich, \& Geis, 1991; Maschke, Goeters, \& Klamm, 2000; and also Pecena, 2007).

\section{Psychological Criteria for the ESA Selection Campaign}

The most important source for defining the psychological factors were expert judgments on the basis of the criteria established for the former ESA selection in 1991. The second important source was the human behavior and performance (HBP) requirements document for the participation in international long-duration missions defined by all ISS agencies (Mission Operations Directorate, 2008). The competency model presented there forms the basis for determining the HBP training curriculum for long-duration crew members and was also of help in determining the selection criteria. The result of both sources formed the present set of operational aptitudes, personality factors, necessary needs, motivations, and interpersonal and performance-oriented factors (for details, see the Methods section).

\section{Basic Formal Requirements}

The following formal qualifications ${ }^{1}$ were necessary to apply to become an ESA astronaut:

- A university degree in natural science (physics, biology, chemistry, and mathematics) or in engineering or medicine;

- Three years postgraduate professional experience or experience as a pilot;

- Nationality: ESA Member State;

- Age: maximum 55 years;

- A private pilot medical certificate (the so-called JARFCL 3 Class 2 medical certificate, a European-wide accepted standard developed by the Joint Aviation Authority).

\section{Setup of the Selection Process}

The psychological selection was conducted by the German Aerospace Centre DLR in cooperation with the French space organization MEDES and divided into two phases.

Phase 1 was designed to provide an efficient group screening on basic aptitude measures. Therefore the candidates had to participate in a pre-test Web-based test training session. All candidates received an online account at the ESA website to download/perform online training on the cognitive tests. The reason for this procedure is that test faking and cheating has an enormous impact on test performance. Therefore only transparent training strategies can maintain a high level of test validity, especially in the intercultural context of a European astronaut selection (see Huelmann \& Oubaid, 2004; Oubaid, 2006).

The overall psychological test battery is applied in a sequential test procedure and consists of two phases (see Figure 1). For Phase 1, cutoff scores for each single trait/ aptitude were established to decide whether or not to recommend candidates for Phase 2. The Phase 1 decision was taken after all candidates passed this phase; this guaranteed making the decisions based on specific norms derived from this unique population. These norms were necessary because of the extreme heterogeneity of the candidate population (age, nationality, education, profession, etc.).

Phase 2 took place at the ESA EAC (European Astronaut Centre) in Cologne, Germany, and focused less on performance and more on interactive competences and personality traits suitable for future astronauts. It consisted of team exercises (two group exercises and one dyadic

1 See also http://www.esa.int/esaMI/Astronaut_Selection/index.html. 


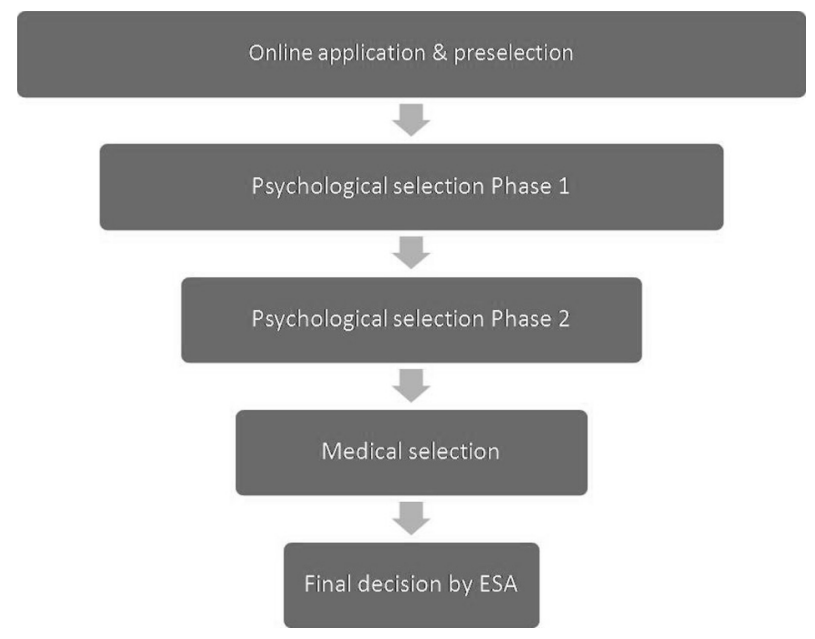

Figure 1. Stages in the European Space Agency (ESA) astronaut selection campaign.

exercise), a projective test (conducted by MEDES), and interviews. The methods (and results) of Phase 2 will be reported in a separate article.

Figure 1 highlights the phases of the ESA selection campaign.

\section{Methods}

\section{Participants}

Within the period of online application from May to June 2008, 8,413 candidates registered, completed the online application form, and provided a medical certificate.

Based on a complex online points system (e.g., bonus points for $\mathrm{PhD}$ or pilot licences), 902 candidates were invited to Phase 1 of psychological selection at DLR in Hamburg. Of the 902 candidates, 162 were female. This percentage was higher than that of the total group of candidates $(16 \%)$. The age of the invited candidates ranged from 24 to 46 years, with a mean of 33.2 and a standard deviation of 3.6. Table 1 shows the distribution of nationalities.

\section{Test Material}

All test material was presented in English. The candidates in Phase 1 were invited for the basic aptitude testing in groups of up to 44 candidates.

Phase 1 was conducted at DLR in Hamburg, using the computerized test platform Hosted Testing (HOT; see Figure 2).

The test program consisted of the set of basic aptitude tests and additional personality questionnaires shown in Table 2.

The basic aptitude tests used in Phase 1 are based on DLR's experience gained in earlier astronaut selections
Table 1. ESA astronaut candidates, Phase $1(n=902)$

\begin{tabular}{lcc}
\hline Country & No. of candidates & \% of total candidates \\
\hline France & 201 & 22.3 \\
Germany & 186 & 20.6 \\
United Kingdom & 102 & 11.3 \\
Italy & 77 & 8.5 \\
Spain & 60 & 6.7 \\
Switzerland & 56 & 6.2 \\
Sweden & 35 & 3.9 \\
Belgium & 31 & 3.4 \\
Austria & 31 & 3.4 \\
Finland & 29 & 3.2 \\
Netherlands & 27 & 3.0 \\
Greece & 20 & 2.2 \\
Portugal & 14 & 1.6 \\
Ireland & 12 & 1.3 \\
Denmark & 10 & 1.1 \\
Norway & 8 & 0.9 \\
Luxembourg & 1 & 0.1 \\
Other & 2 & 0.2 \\
Total & 902 & $100.0 \%$ \\
\hline
\end{tabular}

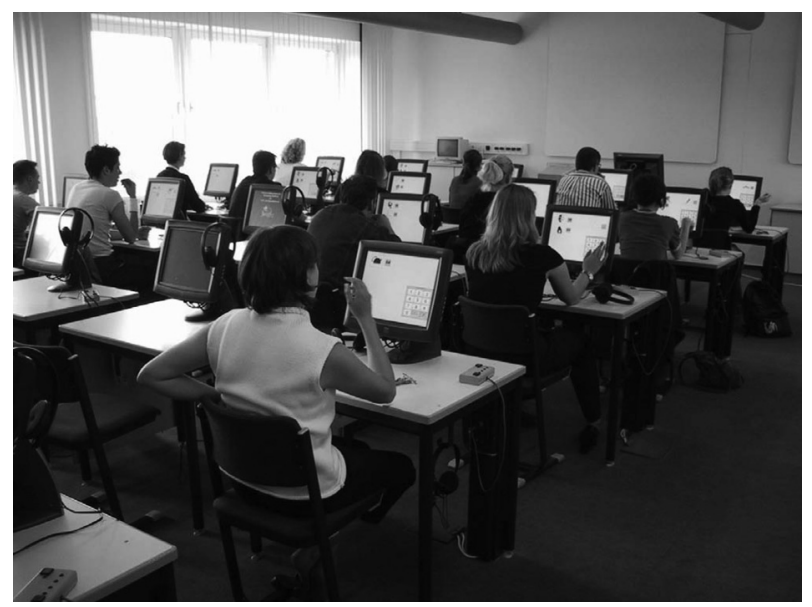

Figure 2. German Aerospace Center DLR, Hamburg, test platform Hosted Testing (HOT).

(DLR has been involved in astronaut selection campaigns on a national and European level since 1977) as well as on experience from selection of pilots and air traffic controllers in an international context. Several validation studies underline the empirical quality of these tests (e.g., Albers, 2008; Hörmann \& Maschke, 1987, 1996; Maschke, 2004). Additionally, two personality questionnaires were administered: the NEO Five Factor Personality Inventory (NEOPI-R; see Costa \& McCrae, 1992) and the Temperament Structure Scales (TSS), which was developed specifically for the selection of aerospace personnel (see Maschke, 1987).

Results derived from personality questionnaires were used during the interview in Phase 2. 
Table 2. Tests and questionnaires used in Phase 1

\begin{tabular}{|c|c|c|}
\hline ESA requirement & Test & Description/subtest/subscales \\
\hline \multicolumn{3}{|l|}{ Operational Aptitudes } \\
\hline Mental arithmetic & & Mental Arithmetic \& Calculation Test \\
\hline Memory function & & Visual Memory Capacity Test \\
\hline Attention & & Symbol Concentration Test \\
\hline Perception & & Optical Perception Test \\
\hline \multirow{2}{*}{ Spatial comprehension } & & Dynamic Way Figures Test \\
\hline & & Dice Rotation Test \\
\hline \multirow[t]{2}{*}{ Reasoning } & & Technical Comprehension Test \\
\hline & & Mental Arithmetic \& Calculation Test \\
\hline Psychomotor coordination & & Monitoring and Instrument Coordination Test \\
\hline Multiple task ability/work capacity & & Monitoring and Instrument Coordination Test \\
\hline English language skills & & English Test \\
\hline \multicolumn{3}{|l|}{ Basic Personality Factors } \\
\hline \multirow[t]{2}{*}{ Extraversion } & NEO PI & $\begin{array}{l}\text { NEO Five Factor Personality Inventory, Subscale } \\
\text { Extraversion }\end{array}$ \\
\hline & TSS & Temperament Structure Scales, Subscale Extraversion \\
\hline \multirow{2}{*}{ Emotional stability } & TSS & Subscale Emotional (In)stability \\
\hline & NEO PI & Subscale Neuroticism \\
\hline Conscientiousness & NEO PI & Subscale Conscientiousness \\
\hline Agreeableness & NEO PI & Subscale Agreeableness \\
\hline Openness & NEO PI & Subscale Openness \\
\hline Self-confidence & TSS & Subscale Emotional (In)stability \\
\hline Flexibility/resilience & TSS & Subscale Rigidity \\
\hline \multicolumn{3}{|l|}{ Motivation } \\
\hline Achievement & TSS & Subscale Achievement Motivation \\
\hline Vocational & TSS & Subscale Achievement Motivation \\
\hline Competitiveness & TSS & Subscale Aggressiveness \\
\hline \multicolumn{3}{|l|}{ Needs } \\
\hline \multirow[t]{2}{*}{ Affiliation } & NEO PI & Subscale Agreeableness \\
\hline & TSS & Subscale Openness \\
\hline Power & TSS & Subscale Dominance \\
\hline Structure & TSS & Subscale Rigidity \\
\hline Status & TSS & Subscale Spoiltness \\
\hline \multicolumn{3}{|l|}{ Performance-Oriented Competencies } \\
\hline Stress resistance & TSS & Subscale Emotional (In)stability \\
\hline Reliability/error avoidance & TSS & Subscales Mobility and Rigidity \\
\hline Goal orientation & TSS & Subscale Achievement Motivation \\
\hline \multicolumn{3}{|l|}{ Interpersonal Competencies } \\
\hline Empathy & TSS & Subscale Empathy \\
\hline
\end{tabular}

Note. ESA = European Space Agency; NEO PI = NEO Five Factor Personality Inventory; TSS = Temperament Structure Scales.

\section{Results}

Of the 902 candidates tested, 192 candidates (21\%) fulfilled the requirements of the Phase 1 selection (Note: in Phase 2, 192 candidates were assessed and 46, or $24 \%$, were psychologically recommended for the next selection step, the medical selection).

\section{Comparison Between Astronaut Candidates and Pilots}

Some of the applied methods (especially in Phase 2) were special developments or adaptations for the astronauts' selection. As some of the tests (especially in Phase 1) were also used in other groups, for these tests, comparison data are available. Table 3 shows a comparison between the NEO-PI-R scores of US Air Force student pilots (Callister, King, Retzlaff, \& Marsh, 1997) and the astronaut candidates of Phase 1. The astronauts scored lower on Neuroticism and higher on Openness to Experience, Agreeableness, and Conscientiousness.

Regarding the personality questionnaire specifically developed for aerospace personnel, the TSS, licensed airline pilot candidates $(n=121)$ of different European nationalities served as a reference group (see Table 4). With the exception of Empathy, astronaut and pilot candidates differed on all TSS scales significantly. The largest differences were 
Table 3. Comparison of astronaut candidates and air force student pilots on the NEO-PI-R

\begin{tabular}{|c|c|c|c|c|c|c|c|}
\hline \multirow[b]{2}{*}{ Scale } & \multicolumn{2}{|c|}{$\begin{array}{l}\text { Astronaut candidates } \\
\qquad(n=902)\end{array}$} & \multicolumn{2}{|c|}{$\begin{array}{l}\text { Pilot candidates } \\
\quad(n=1,301)\end{array}$} & \multirow[t]{2}{*}{$t$ value } & \multirow{2}{*}{$\frac{p \text { value }}{\text { Two-tailed }}$} & \multirow{2}{*}{$\frac{\text { Effect size }}{d}$} \\
\hline & $M$ & $S D$ & $M$ & $S D$ & & & \\
\hline $\mathrm{N}$ & 48.68 & 15.71 & 71.92 & 19.92 & -29.29 & $<.001$ & -1.27 \\
\hline E & 126.97 & 14.06 & 126.31 & 18.15 & .83 & ns & .04 \\
\hline $\mathrm{O}$ & 129.03 & 15.03 & 115.18 & 18.87 & 18.44 & $<.001$ & .80 \\
\hline A & 133.38 & 14.21 & 113.32 & 18.49 & 27.36 & $<.001$ & 1.85 \\
\hline $\mathrm{C}$ & 140.88 & 14.15 & 127.96 & 19.23 & 17.18 & $<.001$ & .74 \\
\hline
\end{tabular}

Notes. Student pilot candidates were US Air Force military pilot candidates. NEO-PI-R = NEO Five Factor Personality Inventory; ns = not significant. Pilot data adapted from Using the NEO-PI-R to assess the personality of US Air Force pilots, by Callister et al. (1997).

Table 4. Comparison of astronaut candidates and airline pilot candidates on the TSS

\begin{tabular}{|c|c|c|c|c|c|c|c|}
\hline \multirow[b]{2}{*}{ Scale } & \multicolumn{2}{|c|}{$\begin{array}{l}\text { Astronaut } \\
\text { candidates } \\
(n=902)\end{array}$} & \multicolumn{2}{|c|}{$\begin{array}{l}\text { Pilot candidates } \\
\quad(n=121)\end{array}$} & \multirow[t]{2}{*}{$t$ value } & \multirow{2}{*}{$\frac{p \text { value }}{\text { Two-tailed }}$} & \multirow{2}{*}{$\frac{\text { Effect size }}{d}$} \\
\hline & $M$ & $S D$ & $M$ & $S D$ & & & \\
\hline Achievement motivation & 14.6 & 3.1 & 13.4 & 3.1 & -4.0 & $<.001$ & .39 \\
\hline Emotional instability & 5.6 & 3.2 & 7.7 & 4.3 & 6.7 & $<.001$ & -.55 \\
\hline Rigidity & 14.2 & 4.7 & 16.7 & 4.0 & 5.7 & $<.001$ & -.57 \\
\hline Extraversion & 16.0 & 4.5 & 17.5 & 4.0 & 3.5 & $<.001$ & -.035 \\
\hline Aggressiveness & 6.34 & 4.0 & 7.6 & 4.4 & 3.5 & $<.001$ & -.031 \\
\hline Vitality & 14.8 & 4.4 & 12.5 & 5.1 & -5.2 & $<.001$ & .48 \\
\hline Dominance & 14.4 & 4.2 & 16.1 & 3.6 & 4.3 & $<.001$ & -.43 \\
\hline Empathy & 13.5 & 3.2 & 13.7 & 3.1 & .8 & ns & -.06 \\
\hline Spoiltness & 4.6 & 2.4 & 6.5 & 2.6 & 7.9 & $<.001$ & -.76 \\
\hline Mobility & 9.1 & 2.8 & 5.8 & 3.0 & -11.9 & $<.001$ & 1.14 \\
\hline Openness & 7.04 & 4.1 & 9.0 & 4.7 & 5.0 & $<.001$ & -.45 \\
\hline
\end{tabular}

Note. $\mathrm{ns}=$ not significant.

Table 5. Comparison of astronaut candidates and airline pilot candidates on performance tests

\begin{tabular}{|c|c|c|c|c|c|c|c|}
\hline \multirow[b]{2}{*}{ Tests } & \multicolumn{2}{|c|}{$\begin{array}{l}\text { Astronaut } \\
\text { candidates } \\
(n=902)\end{array}$} & \multicolumn{2}{|c|}{$\begin{array}{l}\text { Pilot candidates } \\
\quad(n=121)\end{array}$} & \multirow[t]{2}{*}{$t$ value } & \multirow{2}{*}{$\frac{p \text { value }}{\text { Two-tailed }}$} & \multirow{2}{*}{$\frac{\text { Effect size }}{d}$} \\
\hline & $M$ & $S D$ & $M$ & $S D$ & & & \\
\hline English language & 48.4 & 8.6 & 46.4 & 8.4 & -2.3 & .05 & .24 \\
\hline Technical comprehension & 28.7 & 6.4 & 24.4 & 5.3 & -7.1 & $<.001$ & .73 \\
\hline Mental arithmetic & 21.0 & 6.0 & 17.4 & 5.8 & -6.3 & $<.001$ & .61 \\
\hline Memory function & 86.9 & 19.7 & 96.8 & 24.1 & 5.0 & $<.001$ & -.45 \\
\hline Perceptual speed & 36.3 & 9.8 & 44.8 & 9.8 & 9.1 & $<.001$ & -.87 \\
\hline Spatial comprehension & 22.1 & 10.1 & 32.1 & 9.8 & 10.3 & $<.001$ & -1.00 \\
\hline
\end{tabular}

observed in Mobility and Vitality (higher astronaut scores) and Rigidity, Emotional Instability, and Openness (higher pilot scores).

Comparisons of the means of astronaut and airline pilot candidates on performance tests are shown in Table 5. Astronaut candidates scored significantly higher on tests of English language, technical comprehension, and mental arithmetic, whereas airline pilot candidates performed better on memory function, perceptual speed, and spatial comprehension.

\section{Discussion}

In general, this largest astronaut selection campaign worldwide was planned and conducted successfully. At the end of the psychological selection, a group of 46 individuals from different European countries were recommended for further selection steps. The low proportion of female candidates seems to be disappointing at first glance. However, compared with other technical and operational professions 
(e.g., engineers and pilots), it seems to be within the expected range.

Surprisingly there was almost no loss of candidates during the selection steps: The willingness of highly qualified (and therefore often occupied by other activities) candidates, to accept an invitation irrespective of the date, shows the attractiveness of the astronaut's career.

On the personality scales of the NEO-PI-R, high discrepancies were observed in most scales in comparison with Air Force student pilots. Are astronaut candidates really different in personality? Various factors might have caused these results: Besides each group having different personalities, the selection situation itself might have had a considerable effect. The comparison group filled in the questionnaire in a situation with no consequences expected, whereas the astronaut candidates performed the test in a selection situation. This bias due to different tendencies of social desirability did not exist in the second personality questionnaire, the TSS. Both the astronauts and the reference group (licensed airline pilot candidates) were in a selection situation and expected their answers to have consequences. In this comparison, the differences were generally mostly moderate but still significant. This supports the assumption that astronaut candidates are to some extent of "specific personality."

Regarding performance tests, the astronaut candidates showed better results in knowledge-related tests (English language, technical comprehension, and mental arithmetic). This can be explained by the general high educational level of the astronaut candidates (university degree required). On the other hand, the airline pilots performed better on operational tests. This might be a result of the high operational demands in airline pilot training, whereas operational aptitudes did not play a main role in the scientific career of the astronaut candidates.

The adaptation of methods applied in pilot and/or air traffic controller selection to astronaut selection seems to be the best approach, as the selection campaigns for astronauts are infrequent and the specific test developments are elaborate. Nevertheless, a scientific analysis of the astronauts' job requirements could lead to a more systematic decision about the application of existing methods and/or the development of specific tests in the future. For instance, as psychomotor skills are of high relevance for astronauts on extravehicular missions, test developments should focus on this issue. Although the applied methods can be used, the significant differences between astronaut applicants and pilot applicants/general population in aptitude tests and personality questionnaires underline the need for specific test developments in the future.

\section{References}

Albers, F. (2008). Development and evaluation of computerized test battery for multiple task performance in pilot selection. International Journal of Psychology, 43, 97-98.

Callister, J. D., King, R. E., Retzlaff, P. D., \& Marsh, R. W. (1997). Using the NEO-PI-R to assess the personality of US Air Force pilots. Washington, DC: US Government Printing Office (AL/AO-TR-1997-0097).
Chidester, T. R., Helmreich, R. L., Gregorich, S. E., \& Geis, C. E. (1991). Pilot personality and crew coordination: Implications for training and selection. The International Journal of Aviation Psychology, 1, 25-44.

Costa, P. T., \& McCrae, R. R. (1992). NEO-PI-R. Odessa, FL: PAR.

Fassbender, C., \& Goeters, K.-M. (1992). Results of the ESA study on psychological selection of astronaut candidates for Columbus mission I: Aptitude testing. Acta Astronautica, 27, 131-138.

Fassbender, C., \& Goeters, K.-M. (1994). Psychological evaluation of European astronaut applicants: Results of the 1991 selection campaign. Aviation Space Environmental Medicine, 65, 925-929.

Goeters, K.-M., \& Fassbender, C. (1992). Results of the ESA study on psychological selection of astronaut candidates for Columbus mission II: Personality assessment. Acta Astronautica, 27, 139-145.

Hörmann, H. J., \& Maschke, P. (1987). Bewährungskontrolle eines eignungsdiagnostischen Auswahlverfahrens für angehende Verkehrsflugzeugführer [A validity study of a selection procedure for student airline pilots]. Hamburg, Germany: DLR. DLR Research Report no. DFVLR-FB-87-34.

Hörmann, H. J., \& Maschke, P. (1996). On the relation between personality and job performance of airline pilots. The International Journal of Aviation Psychology, 6, 171-178.

Huelmann, G., \& Oubaid, V. (2004). Computer assisted testing (CAT). In K.-M. Goeters (Ed.), Aviation psychology: Practice and research (pp. 123-134). Aldershot, UK: Ashgate.

Kanes, N., \& Manzey, D. (2008). Space psychology and psychiatry. Dordrecht, The Netherlands: Kluwer.

Maschke, P. (1987). Temperament Structure Scales (TSS). European Space Agency, Tech. Rep. ESA-TT-1069. Oberpfaffenhofen, Germany: ESA.

Maschke, P. (2004). Personality evaluation of applicants in aviation. In K.-M. Goeters (Ed.), Aviation psychology: Practice and research (pp. 141-152). Aldershot, UK: Ashgate.

Maschke, P., Goeters, K.-M., \& Klamm, A. (2000). Job requirements of airline pilots: Results of a job analysis. In B. Hayward \& A. Lowe (Eds.), Aviation resource management (pp. 1-8). Aldershot, UK: Ashgate.

Missions Operation Directorate: International Space Station Human Behaviour \& Performance Competency Model. (2008). Volume $1 \& 2$, Mission Operations Directorate, ITCB HBP Training Working Group.

Oubaid, V. (2006). The problem of commercial test training. Facts, data and anti-faking strategies. In K. Thomas \& K.-M. Goeters (Eds.), Proceedings of the 27th Conference of the European Association for Aviation Psychology, Sept. 24-28, 2006. Potsdam: Germany.

Pecena, Y. (2007). Astronaut selection: Method and perspectives - importance of interpersonal competencies. Presentation at the Congress: Medicine and Mobility, Cologne, Germany. In B. Koch \& R. Gerzer (Eds.), Tagungsband zum 9. Kongress "Medizin und Mobilität" (p. 27). Cologne, September 13-15, 2007.

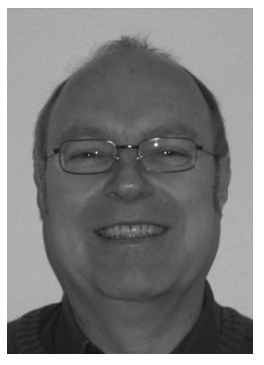

Peter Maschke (PhD, 1986) is Head of the Department of Aviation and Space Psychology of the German Aerospace Center (DLR) in Hamburg, Germany. His main professional and research activities are personality measurement, the predictive validity of pilot selection methods, and development and training of CrewResource-Management programs. Since 1999 he is registered as EAAP Aviation Psychologist. During 2008/2009 he was 
responsible for the psychological selection within the 3rd European astronaut selection campaign. He had several university teaching positions and published several articles especially about validity, personality, and job requirements.

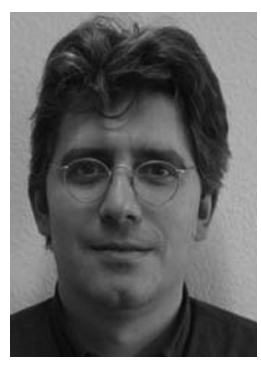

Viktor Oubaid (PhD; member of DGPS and EAAP) is working at the DLRGerman Aerospace Centre, Department of Aviation and Space Psychology, Hamburg, since 1999. He is also responsible for the standards and diagnostic design of pilot selection for Lufthansa German Airlines and other national and international airlines. His research interests and projects cover computer based ability testing and computer based group assessments as well as personality research for pilots. During the last years his work was focussed on the development and evaluation of a new, computer based assessment-center technique in the field of pilot selection. In 2008/2009 he was a member of the ESA Astronaut selection core team. Since 2001 he is also responsible for the Quality management and ISO 9000 certification at DLR Hamburg.

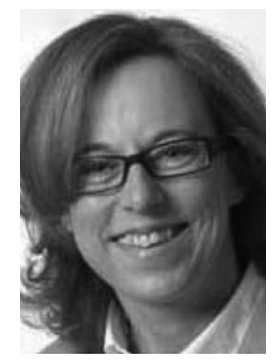

Yvonne Pecena received her M.Sc. in Psychology from the Free University of Berlin, Germany, in 1993. She works as an aviation psychologist at the Department of Aviation and Space Psychology, German Aerospace Centre DLR, Hamburg, where she began applied research focussing on psychological selection and training of aerospace personnel. Her thesis was concerned with the development and evaluation of a behavior oriented approach to assess team competencies. Additionally, she has a clinical background. She is currently engaged in the selection of air traffic controllers for the German air navigation service provider (ANSP) Deutsche Flugsicherung (DFS), where she is responsible for personality assessment. Since 2007 she is involved in the psychological support activities during ISS expeditions in cooperation with the Crew Medical Support Office of the European Space Agency (ESA).

Correspondence Address 